\title{
Integrated Process Study on Hydrate-Based Carbon Dioxide Separation from Integrated Gasification Combined Cycle (IGCC) Synthesis Gas in Scaled-Up Equipment
}

\author{
Chun-Gang Xu, ${ }^{\dagger, \ddagger}$ Jing Cai, ${ }^{\dagger, \dagger}$ Xiao-Sen Li, ${ }^{*},{ }^{\dagger,}$ Qiu-Nan Lv, ${ }^{\dagger, \dagger}$ Zhao-Yang Chen, ${ }^{\dagger, \downarrow}$ and Hai-Wei Deng ${ }^{\xi}$ \\ ${ }^{\dagger}$ Key Laboratory of Renewable Energy and Gas Hydrate, Guangzhou Institute of Energy Conversion, and ${ }^{\ddagger}$ Guangzhou Center for Gas \\ Hydrate Research, Chinese Academy of Sciences, Guangzhou 510640, People's Republic of China \\ ${ }^{\xi}$ Department of Chemistry, Jiangsu Institute of Education, Nanjing 210013, People's Republic of China
}

ABSTRACT: In this work, the effects of stirring and bubbling methods on hydrate-based carbon dioxide $\left(\mathrm{CO}_{2}\right)$ separation from integrated gasification combined cycle (IGCC) synthesis gas are compared. Then, an integrated process of bubbling in conjunction with temperature fluctuation is proposed and adopted in the experiments, which are conducted in bench and scaledup equipment. The experimental results show that the bubbling method has a similar positive effect on the $\mathrm{CO}_{2}$ separation as the stirring method. The optimal volume ratio of tetra- $n$-butylammonium bromide (TBAB) solution to the reactor shifts to 0.75 after the volume of the reactor is enlarged 100 -fold, and at that ratio, the total $15.3 \mathrm{~mol}$ of gas is consumed and the mole concentration of $\mathrm{CO}_{2}$ in the gas phase reduces from 40.0 to $13.2 \%$. The results indicate that the integrated process and scaled-up equipment are feasible for hydrate-based $\mathrm{CO}_{2}$ separation.

\section{INTRODUCTION}

Carbon dioxide $\left(\mathrm{CO}_{2}\right)$ is considered as the one of the main greenhouse gases. Among all of the $\mathrm{CO}_{2}$ emissions worldwide, nearly one-third of $\mathrm{CO}_{2}$ emissions come from fossil fuel electric power plants. ${ }^{1}$ To limit global warming, $\mathrm{CO}_{2}$ emission reduction is extremely urgent. Presently, the major approaches for $\mathrm{CO}_{2}$ capture from the flue gases include post-combustion capture, pre-combustion capture, and oxy-fuel combustion capture. With oxy-fuel combustion, $\mathrm{CO}_{2}$ can be completely captured because the components of the gas emitted from the oxy-fuel combustion are $\mathrm{CO}_{2}$ and water vapor $\left(\mathrm{H}_{2} \mathrm{O}\right)$. However, post-combustion capture and pre-combustion capture are more extensively used because of their relatively lower cost and simple processes. The main gases released from the post-combustion and precombustion are the $\mathrm{CO}_{2} / \mathrm{N}_{2}$ gas mixture and the $\mathrm{CO}_{2} / \mathrm{H}_{2}$ gas mixture; thus, $\mathrm{CO}_{2}$ can only be sequestered after it is completely separated from the gas mixtures. Therefore, a high-efficiency and economical $\mathrm{CO}_{2}$ separation technology is crucial to $\mathrm{CO}_{2}$ emission reduction. The conventional technologies, including chemical absorption, physical adsorption, cryogenic fractionation, have been used commercially in industry. ${ }^{2}$ However, these technologies each have their individual issues, such as high energy consumption, low separation efficiencies, low capacity, and high corrosion. Hence, researching and developing new $\mathrm{CO}_{2}$ separation technologies are pressing issues. Gas-hydrate-based $\mathrm{CO}_{2}$ separation technology is a new technology that is being extensively studied at present.

Gas hydrates are non-stoichiometric compounds, which are formed by water molecules (host) and small gas molecules (guests) [e.g., methane $\left(\mathrm{CH}_{4}\right)$, hydrogen $\left(\mathrm{H}_{2}\right)$, carbon dioxide $\left(\mathrm{CO}_{2}\right)$, oxygen $\left(\mathrm{O}_{2}\right)$, and hydrogen sulfide $\left.\left(\mathrm{H}_{2} \mathrm{~S}\right)\right]$ under conditions of low temperature and high pressure. ${ }^{3,4}$ In gas hydrates, the water molecules connect each other by hydrogen bonds and form different cavities; meanwhile, the small gas molecules stably occupy the cavities by van der Waals interaction forces. ${ }^{5}$ The basis of gas-hydrate-based $\mathrm{CO}_{2}$ separation technology is the selective partition of the $\mathrm{CO}_{2}$ component between the hydrate phase and the gaseous phase. For instance, at the same temperature, the equilibrium hydrate formation pressure of $\mathrm{CO}_{2}$ is lower than those of $\mathrm{H}_{2}$ and $\mathrm{N}_{2} ;{ }^{6,7}$ thus, $\mathrm{CO}_{2}$ can be preferentially entrapped into the cavities to form gas hydrates compared to $\mathrm{H}_{2}$ and $\mathrm{N}_{2}$ under the same conditions. The hydrates are separated and subsequently dissociated to release the $\mathrm{CO}_{2}$-rich stream, while the rest constitutes the $\mathrm{CO}_{2}$-lean stream. Thereby, $\mathrm{CO}_{2}$ can be captured from gas mixtures. In accordance with the difference in cavity shape and size, the gas hydrates have been classified into four distinct structures: structure I (sI), structure II (sII), structure $\mathrm{H}(\mathrm{sH})$, and semiclathrate $(\mathrm{sc}) .^{8-10}$ The hydrate structures are largely determined by the guests. Therefore, different guests have their different hydrate structures. Generally, $\mathrm{CO}_{2}$ forms sI hydrate, while $\mathrm{H}_{2}$ and $\mathrm{N}_{2}$ form sII structures.

Over the past 20 years, there has been considerable interest in the thermodynamics and kinetics of hydrate-based $\mathrm{CO}_{2}$ separation and capture from gas mixtures. ${ }^{7,8,11,12}$ For the thermodynamics, a large amount of equilibrium hydrate formation has been obtained. ${ }^{12-16}$ For the kinetics, research has focused on induction time, hydrate formation rate, and driving force. Recent work has included hydrate-based $\mathrm{CO}_{2}$ separation processes. However, there are still many obstacles standing in the way of the development of the hydrate-based $\mathrm{CO}_{2}$ separation process, such as the low gas uptake, the long induction time, and the slow hydrate formation rate. To accelerate the hydrate formation and shorten the induction time, many hydrate formation additives [e.g., tetrahydrofuran (THF), tetra- $n$ butylammonium bromide (TBAB), sodium dodecyl sulfate

Received: July 18, 2012

Revised: September 7, 2012

Published: September 20, 2012 
(SDS), etc.] have been employed in previous work, resulting in notable achievements. ${ }^{2,6,17-20}$ In addition, different mechanical methods of agitation, such as stirring, bubbling, and spraying, have been adopted to enhance the gas-liquid contact and further promote the gas hydrate formation. ${ }^{21-25}$ Nevertheless, the achievements obtained from the previous work do not yet match the requirements of industrial application. For this reason, the hydrate-based $\mathrm{CO}_{2}$ separation process needs to be further optimized, especially with respect to the hydrate formation rate and $\mathrm{CO}_{2}$ separation efficiency. Moreover, most of the previous studies on hydrate-based $\mathrm{CO}_{2}$ separation from flue gases were conducted in a small experimental apparatus, with few results reported in scaled-up equipment.

According to the study by Kojima et al., $\mathrm{CO}_{2}$ solubility in the hydrate-forming region increases as the temperature increases. ${ }^{26}$ Thus, in the process of hydrate formation, an increase of the temperature may be helpful to the $\mathrm{CO}_{2}$ dissolution in a solution. On the basis of our previous research, an integrated process (involving a bubble method and temperature fluctuation) is proposed to separate $\mathrm{CO}_{2}$ from integrated gasification combined cycle (IGCC) synthesis gas [mainly as a $\mathrm{CO}_{2}(40.0 \%) / \mathrm{H}_{2}$ $(60.0 \%)$ gas mixture] in a scaled-up reactor. ${ }^{27,28}$ For the reason that stirring the solution consumes a significant amount of energy, a bubble method is adopted to replace stirring in the work. In this work, gas uptake, $\mathrm{CO}_{2}$ separation efficiency, and $\mathrm{CO}_{2}$ concentration in the residual gas phase are thoroughly analyzed. In addition, comparisons of results achieved from experiments conducted in small and scaled-up equipment are made to prove the feasibility of the integrated process for hydrate-based $\mathrm{CO}_{2}$ separation.

\section{EXPERIMENTAL SECTION}

2.1. Materials. A pretreated IGCC synthesis gas is simulated by a $\mathrm{CO}_{2}(40.0 \%) / \mathrm{H}_{2}(60.0 \%)$ gas mixture. The gas mixture is ultrahigh purity (UHP)-grade and is supplied by Huate Special Gas Co., Ltd. TBAB is supplied by Shanghai Sinopharm Chemical Reagent Co., Ltd., China, with $99.0 \%$ purity. The deionized water with $18.3 \mathrm{~m} \Omega \mathrm{cm}^{-1}$ resistivity is produced by ultrapure water equipment, which is supplied by Nanjing Ultrapure Water Technology Co., Ltd., China.

2.2. Apparatus. The experimental apparatuses are shown in Figures 1 and 2 . Figures 1 and 2 are the schematics of the small experimental apparatus and the scaled-up equipment, respectively. For Figure 1, the

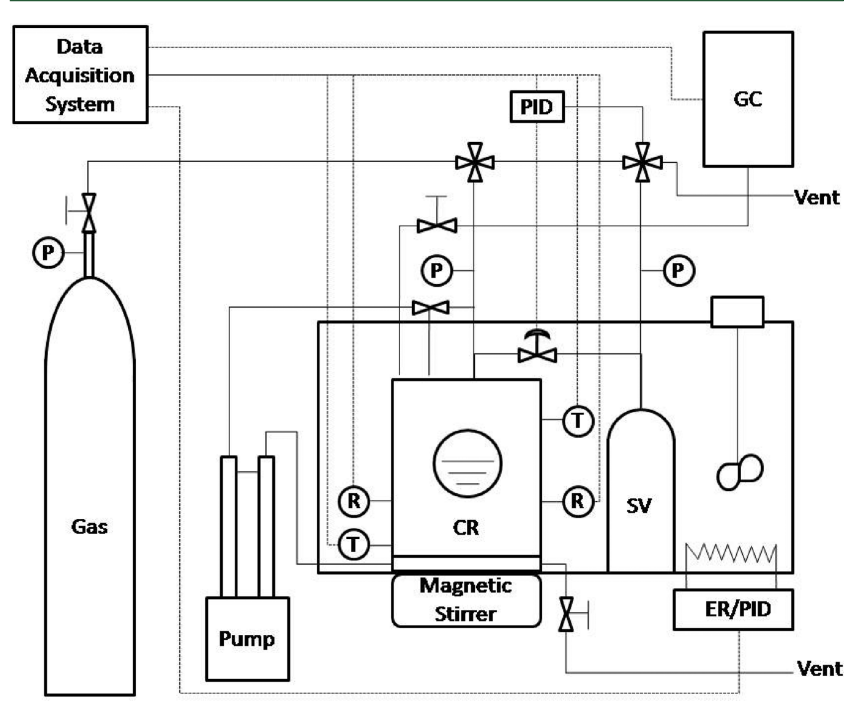

Figure 1. Schematic of the small experimental apparatus. crystallizer (CR) with $336 \mathrm{~mL}$ inner volume and a $1350 \mathrm{~mL}$ supply vessel (SV) is made of 316 stainless steel immersed in a temperaturecontrolled water bath. Two circular viewing windows made of Plexiglas are set on the front and back of the CR. A pump is connected on the CR to bubble the gas into the $\mathrm{CR}$ and drive gas out from the $\mathrm{CR}$. The maximum working pressures of the $\mathrm{CR}$ and the $\mathrm{SV}$ are set at $25 \mathrm{MPa}$. The pressures are measured with two Setra smarte pressure transducers (model 552, Boxborough, MA) with an accuracy of $0.02 \mathrm{MPa}$. Temperatures are measured by using three Pt1000 thermocouples (JM6081) with uncertainties of $0.1 \mathrm{~K}$. Under the CR, a magnetic stirrer $(0-1000$ revolutions $/ \mathrm{min})$ is employed to mix the contents thoroughly. The compositions of the residual gas phase and the decomposition gas phase are determined with HP6890 gas chromatography (GC) connected online with the $\mathrm{CR}$ and automated using a personal computer (PC). For Figure 2, the scale-up equipment consists of a $40 \mathrm{~L}$ cuboid reactor $(10.0 \mathrm{~cm}$ in side length and $4.0 \mathrm{~m}$ in height $)$ made of 316 stainless steel, a refrigeration system, a temperature control unit, and two pumps. The reactor is equipped with transparent Plexiglas in front and back sides and is jacketed with a glycol-water bath on the right and left sides, and it is evenly divided into four segments from the bottom to the top (segments I, II, III, and IV). The maximum working pressure for the reactor is $4.0 \mathrm{MPa}$. A scale with a precision of $1 \mathrm{~cm}$ is attached to a side of the reactor to indicate the height of the liquid and to point to the position of bubbles. The temperature in the reactor is controlled by the glycol-water flowing circularly within the jacket. A Pt1000 thermoprobe with $\pm 0.05^{\circ} \mathrm{C}$ accuracy is positioned on the top of each segment to measure the temperature. The pressure is measured using a pressure transducer, with a range of $0-10 \mathrm{MPa}$ and an accuracy of $\pm 0.02 \mathrm{MPa}$. A proportional-integral-derivative (PID) controller is used to maintain a stable pressure. A gas flowmeter (LineTech M3030) determines the gas volume introduced from the gas cylinder. The flow rate range for the flowmeter is $\left(0-22.5 \mathrm{~mL} \mathrm{~min}^{-1} \mathrm{~L}^{-1}\right)$. The bubble size is controlled by a round bubble plate distributor $(10 \mathrm{~cm}$ in diameter) with $50 \mu \mathrm{m}$ holes.

2.3. Procedure. 2.3.1. Experiments Conducted in the Small Apparatus. The methods of bubbling and stirring are both used in the experiments, and a comparison of results achieved from the two methods is conducted to verify that the method of bubbling has a positive effect on the hydrate-based $\mathrm{CO}_{2}$ separation from the $\mathrm{CO}_{2} / \mathrm{H}_{2}$ gas mixture similar to stirring.

In the stirring experiments, $180 \mathrm{~mL}$ of TBAB solution $(0.29 \mathrm{~mol} \%)$ is put into the $336 \mathrm{~mL}$ reactor, and then the reactor is sealed tightly and immersed into the water bath. After the temperature in the reactor reaches the desired value, the free gas in the reactor is pumped out thoroughly, and then the synthesis gas mixture is pumped into the reactor to the desired pressure. When the temperature recovers to the desired value again, stirring is initiated (rate at $500 \mathrm{rpm}$ ). The gas mixture dissolves into the $\mathrm{TBAB}$ solution and forms gas hydrate as the stirring continues. Meanwhile, the additional gas mixture from the $\mathrm{SV}$ is supplied into the CR to maintain the pressure at a constant value by the PID.

In the bubbling experiments, the difference from the above procedure is that, after the free gas is pumped out thoroughly, the gas mixture (supplied from the SV) is pumped into the solution from the bottom of the reactor as gas bubbles and the gas mixture dissolves into the solution and further forms gas hydrate as the gas bubble moves through the solution. The pressure is again controlled strictly by the PID.

After hydrate formation is completed, the composition of the residual gas is determined with the GC and the gas uptake $\left(\Delta n_{\mathrm{H}}\right)$ is calculated according to the eq 1 as follows: ${ }^{29}$

$$
\begin{aligned}
\Delta n_{\mathrm{H}} & =n_{\mathrm{H}, 0}-n_{\mathrm{H}, t} \\
& =\left(\frac{P V}{z R T}\right)_{\mathrm{CR}, 0}-\left(\frac{P V}{z R T}\right)_{\mathrm{CR}, t}+\left(\frac{P V}{z R T}\right)_{\mathrm{SV}, 0}-\left(\frac{P V}{z R T}\right)_{\mathrm{SV}, t}
\end{aligned}
$$

where $z$ is the compressibility factor calculated by Pitzer's correlation. ${ }^{30}$ Subscript $t$ refers to time $t$, while subscript 0 refers to the initial time of starting the stirrer. Subscript CR refers to the gas phase in the CR, while subscript SV refers to the gas phase in the SV. 


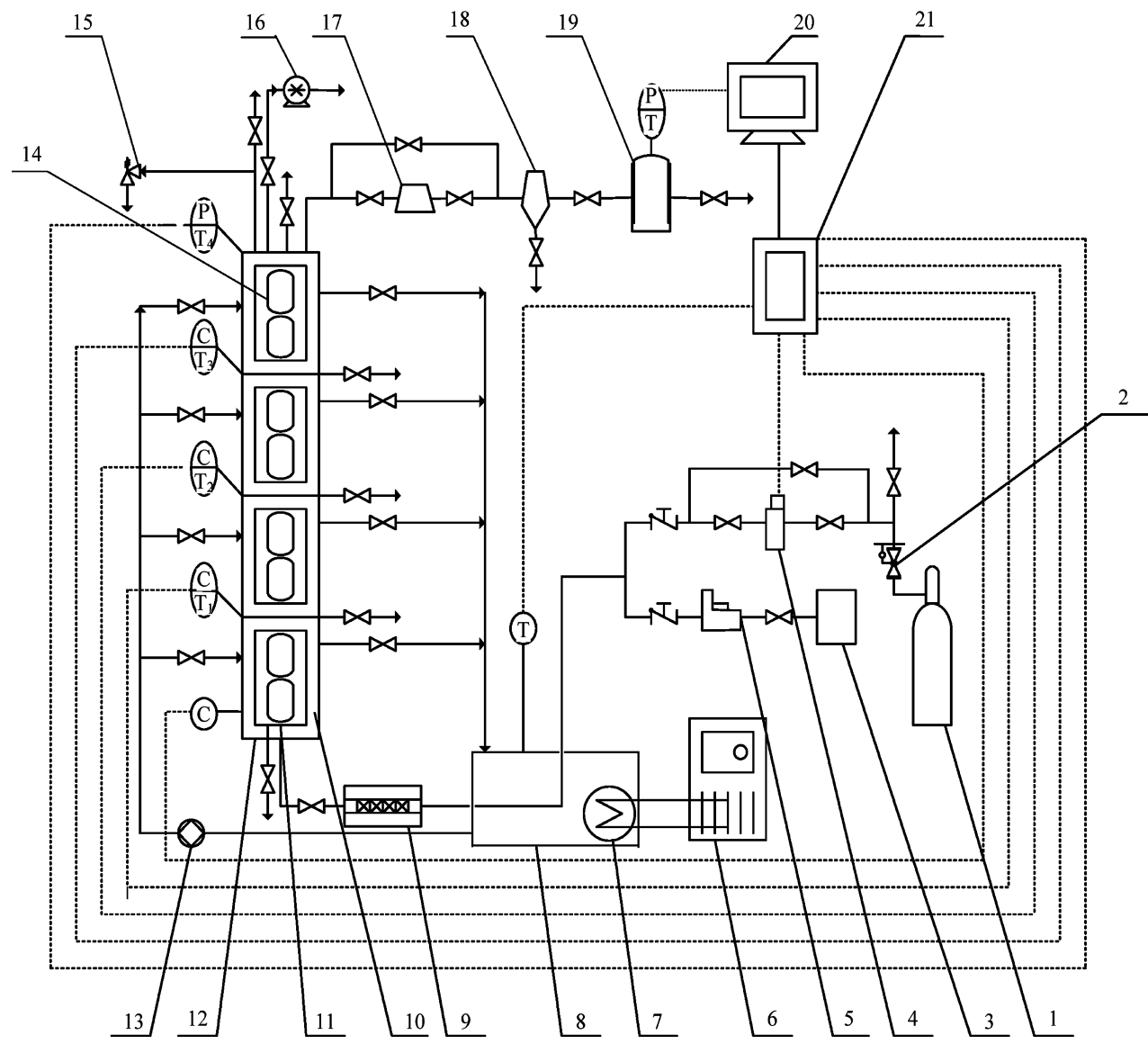

Figure 2. Schematic of the scaled-up apparatus: 1, gas cylinder; 2, relief valve; 3, fluid container; 4, mass flowmeter; 5, controlled volume pump; 6, refrigeration system; 7, heater exchanger; 8, coolant tank; 9, static mixer; 10, water bath; 11, distributor; 12, reactor; 13, coolant recycle pump; 14, visual window; 15 , safety valve; 16, vacuum pump; 17, PID pressure controller; 18, gas-liquid separator; 19, collecting gas cylinder; 20, PC; and 21, date acquisition system.

2.3.2. Experiments Conducted in the Scaled-Up Apparatus. A total of $30 \mathrm{~L}$ of TBAB solution $(0.29 \mathrm{~mol} \%)$ is pumped into the total $40 \mathrm{~L}$ reactor, which is evacuated in advance. After the temperature in the reactor reaches the desired value, the gas mixture is pumped into the solution from the bottom of the reactor and the gas charged is calculated via the gas flowmeter. The bubble size is controlled by a bubble plate. During the process of the hydrate formation, a temperature fluctuation is introduced. The temperature $\left(T^{\prime}\right)$ is increased by $4 \mathrm{~K}$ to a new temperature $\left(T^{\prime \prime}\right)$ that is chosen to be lower than the phase equilibrium temperature. ${ }^{7,16}$ After $0.5 \mathrm{~h}, T^{\prime \prime}$ is decreased to $T^{\prime}$ quickly. Then, the experiment is continued at $T^{\prime}$. The pressure in the reactor is kept constant at lower than $3.10 \mathrm{MPa}$ by the PID. After the experiment is completed, the composition of the residual gas is measured by GC.

2.3.3. $\mathrm{CO}_{2}$ Separation Efficiency Calculation. $\mathrm{CO}_{2}$ separation efficiency is determined by the $\mathrm{CO}_{2}$ split fraction (SFr) and the $\mathrm{CO}_{2}$ separation factor (SF). SFr and SF are calculated according to the following equations: ${ }^{18,29}$

$$
\begin{aligned}
& \mathrm{SFr}=\frac{n_{\mathrm{CO}_{2}}^{\mathrm{H}}}{n_{\mathrm{CO}_{2}}^{\text {feed }}} \\
& \mathrm{SF}=\frac{n_{\mathrm{CO}_{2}}^{\mathrm{H}} n_{\mathrm{H}_{2}}^{\text {gas }}}{n_{\mathrm{H}_{2}}^{\mathrm{H}} n_{\mathrm{CO}}^{\text {gas }}}
\end{aligned}
$$

where $n_{\mathrm{CO}_{2}}^{\text {gas }}, n_{\mathrm{CO}_{2}}^{\mathrm{H}}$, and $n_{\mathrm{CO}_{2}}^{\text {feed }}$ are the moles of $\mathrm{CO}_{2}$ in the gas phase, in the hydrate phase at the end of the hydrate formation, and in the initial gas mixture, respectively. $n_{\mathrm{H}_{2}}^{\text {gas }}$ and $n_{\mathrm{H}_{2}}^{\mathrm{H}}$ are the moles of $\mathrm{H}_{2}$ in the gas phase at the end of the hydrate formation and the moles of $\mathrm{H}_{2}$ in the hydrate phase, respectively.

\section{RESULTS AND DISCUSSION}

3.1. Comparison of Stirring with Bubbling. The experiments were conducted first in the small experimental apparatus (as shown in Figure 1). Taking into account the maximal working pressure of the scaled-up equipment $(4.0$ $\mathrm{MPa}$ ), we set 3.0 $\mathrm{MPa}$ as the experimental pressure in both stirring and bubbling experiments. Figure 3 shows how the gas consumed in the reactor changes with time at two different temperatures. In the stirring experiments, 3.0 MPa gas mixtures were pumped into the system before stirring, giving $0.205 \mathrm{~mol}$ of gas mixtures in the system. When the stirrer starts to work, the gas mixtures dissolve into the solution and form gas hydrates; meanwhile, the additional gas mixtures are supplied from the SV to the reactor to maintain the pressure at $3.0 \mathrm{MPa}$. The amount of additional gas supplied from the SV equals the gas uptake because of hydrate formation. As shown in Figure 3, the final amount of gas consumed in the stirring experiments at 274.65 and $277.65 \mathrm{~K}$ are 0.332 and $0.284 \mathrm{~mol}$, respectively. In the bubbling experiments, because there is no gas mixture in the system before bubbling gas into the reactor, the gas consumed in the system at the beginning is 0 . The final gas mixtures supplied from the SV in the bubbling experiments at 274.65 and $277.65 \mathrm{~K}$ are 0.330 and $0.276 \mathrm{~mol}$, respectively. The results are quite close to those achieved from the stirring experiments, and it means that the method of bubbling has a similar effect on the hydrate formation as the method of stirring, and further proves that 


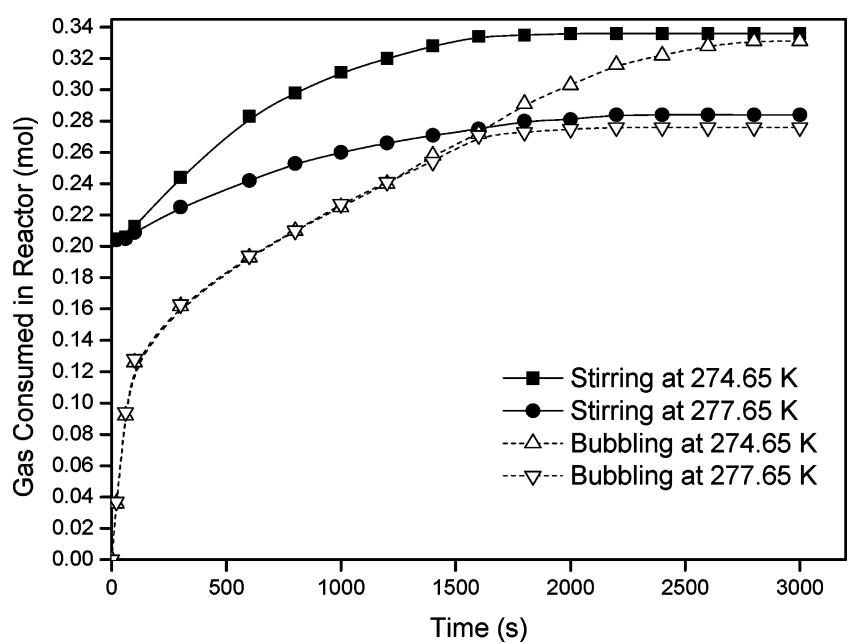

Figure 3. Gas consumed in reactor changes with time achieved from the stirring experiment and the bubbling experiment in the condition of 3.0 $\mathrm{MPa}$.

bubbling can replace stirring to promote the hydrate formation in these experiments.

Figures 4 and 5 show the temperature fluctuation effect on hydrate formation in stirring experiments and bubbling experiments at $274.65 \mathrm{~K}$ and $3.0 \mathrm{MPa}$, respectively. In the experiments, there is a $4 \mathrm{~K}$ temperature increase in the process during hydrate formation. As shown in Figures 4 and 5, the temperature $T^{\prime}$ is increased at the 720th second from $T^{\prime}$ and reaches $T^{\prime \prime}$ at the 1800th second. $T^{\prime \prime}$ is kept for $900 \mathrm{~s}$, and then the temperature is reduced to $T^{\prime}$. With the temperature changes, the pressure in the SV changes accordingly. However, as seen from Figures 4 and 5, the changes of pressure lag behind those of temperature because the pressure increase resulting from the temperature increase is partly offset by the pressure decrease resulting from the hydrate formation. The pressure does not stop dropping when the temperature recoveries to $T^{\prime}$ but drops continuously for a time. As shown in Figures 4 and 5, the pressure drops observed with temperature fluctuation are approximately 12 and $17 \%$ more than those in the experiment without temperature fluctuation, respectively. The result indicates that the temperature fluctuation can contribute to the hydrate formation and a temperature fluctuation during bubbling has a more positive effect on the hydrate formation than what occurs during a similar experiment.

Table 1 shows the gas uptakes along with $\mathrm{CO}_{2}$ concentrations in the residual gas phases and $\mathrm{CO}_{2}$ separation efficiencies achieved from the different experiments. As seen from Table 1, the gas uptakes, the $\mathrm{CO}_{2}$ concentrations, and $\mathrm{CO}_{2}$ separation efficiencies achieved from the stirring experiments and the bubbling experiments are quite close under the same experimental conditions. In comparison to the results achieved in the experiments without temperature fluctuations at the same experimental conditions, the gas uptakes and $\mathrm{CO}_{2}$ separation factors achieved in the experiments with temperature fluctuations are enhanced by $12-17$ and $35-45 \%$, respectively. Although the $\mathrm{CO}_{2}$ SFr values are almost at the same level, the $\mathrm{CO}_{2}$ concentrations in the residual gas phases achieved in the experiments with the temperature fluctuations are approximately $30 \%$ lower than those achieved in the experiments without the temperature fluctuations. The result states that, in comparison to the experiments without the temperature fluctuations, more $\mathrm{CO}_{2}$ gases dissolve into the solutions and form the gas hydrates in experiments with temperature fluctuations, suggesting that the temperature fluctuation enhances hydrate-based $\mathrm{CO}_{2}$ separation from the $\mathrm{CO}_{2} / \mathrm{H}_{2}$ gas mixture.

3.2. $\mathrm{CO}_{2}$ Separation in Scaled-Up Equipment. Figure 6 shows pictures of hydrate formation in the scaled-up equipment at $3.0 \mathrm{MPa}$ and $274.65 \mathrm{~K}$. In Figure 6, five photos taken at different times are arranged in order. Photo 1 is taken at the beginning of bubble gas pumped into the reactor, and the gas bubbles are the only thing captured in the photo. From photo 2 to photo 5, gas hydrates form and are visible. It can be seen that the gas hydrates increase in the reactor gradually from photo 2 to photo 5 . Photo 5 is taken at the end of hydrate formation, where nearly all of the reactor segment is full of gas hydrates.

According to our previous work, the optimal volume ratio of $\mathrm{TBAB}$ solution to the reactor is 0.54 in the small experimental apparatus. ${ }^{20}$ However, the volume ratio of TBAB solution to the scaled-up reactor volume shifts to approximately 0.75 because the volume of the scaled-up reactor is approximately 100 times

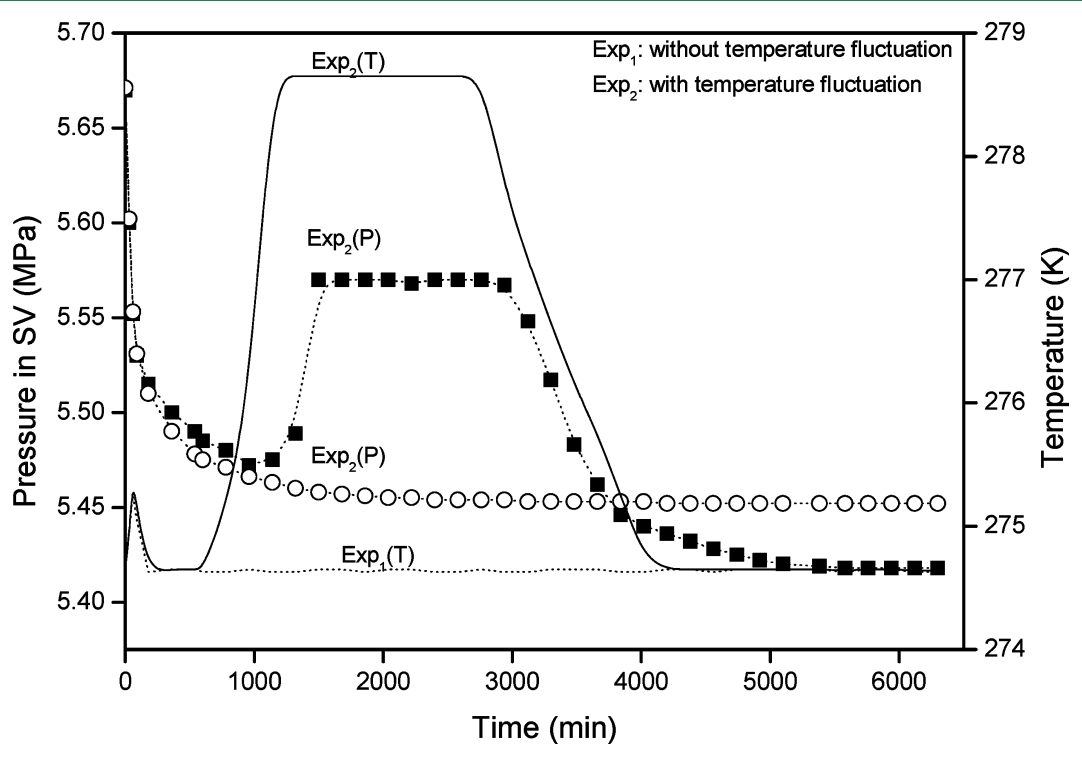

Figure 4. Temperature fluctuation effect on hydrate formation in the stirring experiment at $274.65 \mathrm{~K}$ and $3.0 \mathrm{MPa}$. 


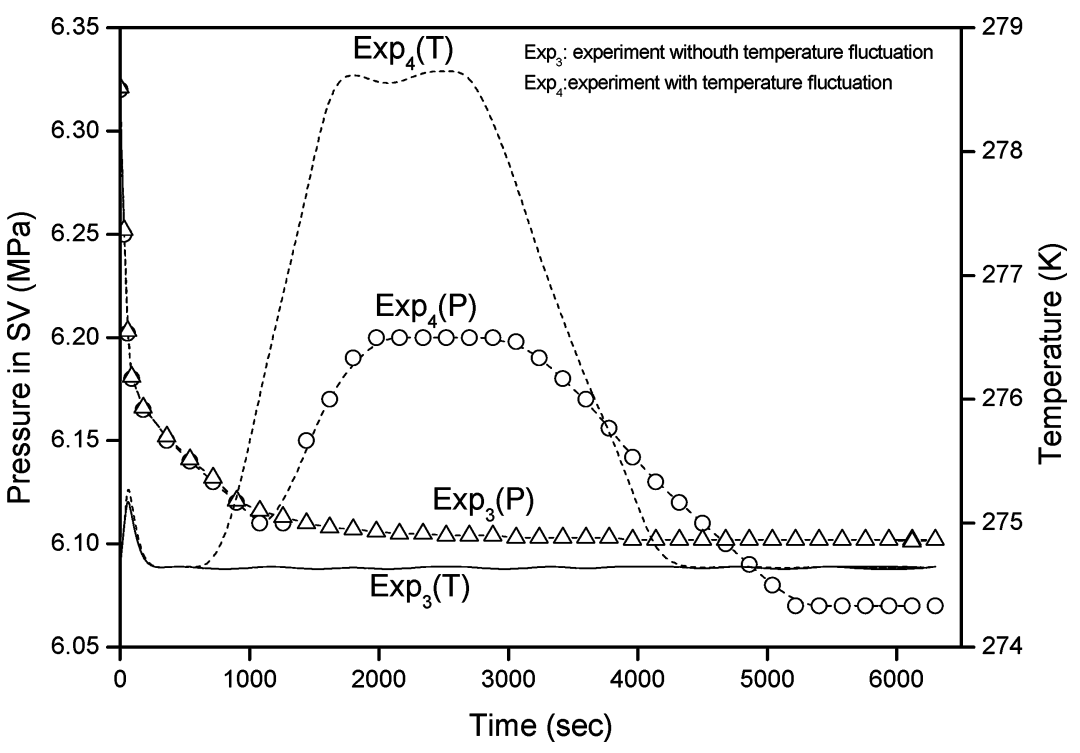

Figure 5. Temperature fluctuation effect on hydrate formation in the bubbling experiment at $274.65 \mathrm{~K}$ and $3.0 \mathrm{MPa}$.

Table 1. Gas Uptake along with the $\mathrm{CO}_{2}$ Concentration in the Residual Gas Phase and $\mathrm{CO}_{2}$ Separation Efficiency Achieved from Different Experiments

\begin{tabular}{|c|c|c|c|c|}
\hline experiment & $\begin{array}{l}\text { gas } \\
\text { uptake } \\
(\mathrm{mol})\end{array}$ & $\begin{array}{l}\mathrm{CO}_{2} \\
\text { concentration in } \\
\text { the residual gas } \\
\text { phase }(\%)\end{array}$ & $\begin{array}{l}\mathrm{CO}_{2} \\
\mathrm{SFr}\end{array}$ & $\mathrm{CO}_{2}$ \\
\hline $\begin{array}{l}\text { stirring experiment at } 3.0 \mathrm{MPa} \\
\text { and } 274.65 \mathrm{~K}\end{array}$ & 0.127 & 11.3 & 0.863 & 49.6 \\
\hline $\begin{array}{l}\text { stirring experiment at } 3.0 \mathrm{MPa} \\
\text { and } 277.65 \mathrm{~K}\end{array}$ & 0.091 & 20.6 & 0.837 & 19.8 \\
\hline $\begin{array}{l}\text { bubbling experiment at } \\
3.0 \mathrm{MPa} \text { and } 274.65 \mathrm{~K}\end{array}$ & 0.125 & 11.4 & 0.869 & 51.6 \\
\hline $\begin{array}{l}\text { bubbling experiment at } \\
3.0 \mathrm{MPa} \text { and } 277.65 \mathrm{~K}\end{array}$ & 0.088 & 21.5 & 0.831 & 17.9 \\
\hline $\begin{array}{l}\text { stirring experiment with } 4 \mathrm{~K} \\
\text { temperature fluctuation at } \\
3.0 \mathrm{MPa} \text { and } 274.65 \mathrm{~K}\end{array}$ & 0.142 & 8.0 & 0.862 & 71.8 \\
\hline $\begin{array}{l}\text { bubbling experiment with } 4 \mathrm{~K} \\
\text { temperature fluctuation at } \\
3.0 \mathrm{MPa} \text { and } 274.65 \mathrm{~K}\end{array}$ & 0.146 & 7.7 & 0.853 & 69.9 \\
\hline
\end{tabular}

that of the small experimental apparatus. Figure 7 shows how the total quantity of gas flow changes with time at different volume ratios. The total quantity of gas flowed is $13.0 \mathrm{~mol}$ when the volume ratio is 0.54 . Nevertheless, the total quantities of gas flowed are 15.3 and $15.1 \mathrm{~mol}$ when the volume ratios are 0.75 and 0.80 , respectively. From 0.54 to 0.75 , the obvious increase of the quantity can mainly be contributed to the obvious increase of the volume of the TBAB solution. More TBAB solution can dissolve more gas mixtures and form more gas hydrates. However, it is not that more solution must necessarily result in more gas consumed. When the volume ratio exceeds 0.75 (i.e., the volume of TBAB solution pumped into the scaled-up reactor exceeds to $30 \mathrm{~L}$ ), the total quantity of gas flow changes little with the increase of the volume but the $\mathrm{CO}_{2}$ concentration in the residual gas phase is higher. As shown in Figure 7, the $\mathrm{CO}_{2}$ concentrations achieved from the experiments with volume ratios of $0.54,0.75$, and 0.8 are $19.4,13.6$, and $16.2 \%$, respectively. The lower $\mathrm{CO}_{2}$ concentration in the residual gas phase corresponds to high $\mathrm{CO}_{2}$ recovery $\left(\mathrm{CO}_{2}\right.$ $\mathrm{SFr}$ ). Thus, it can be concluded from Figure 7 that the volume ratio of 0.75 is optimal relative to the other two volume ratios of 0.54 and 0.80 examined in these experiments. For this reason, the

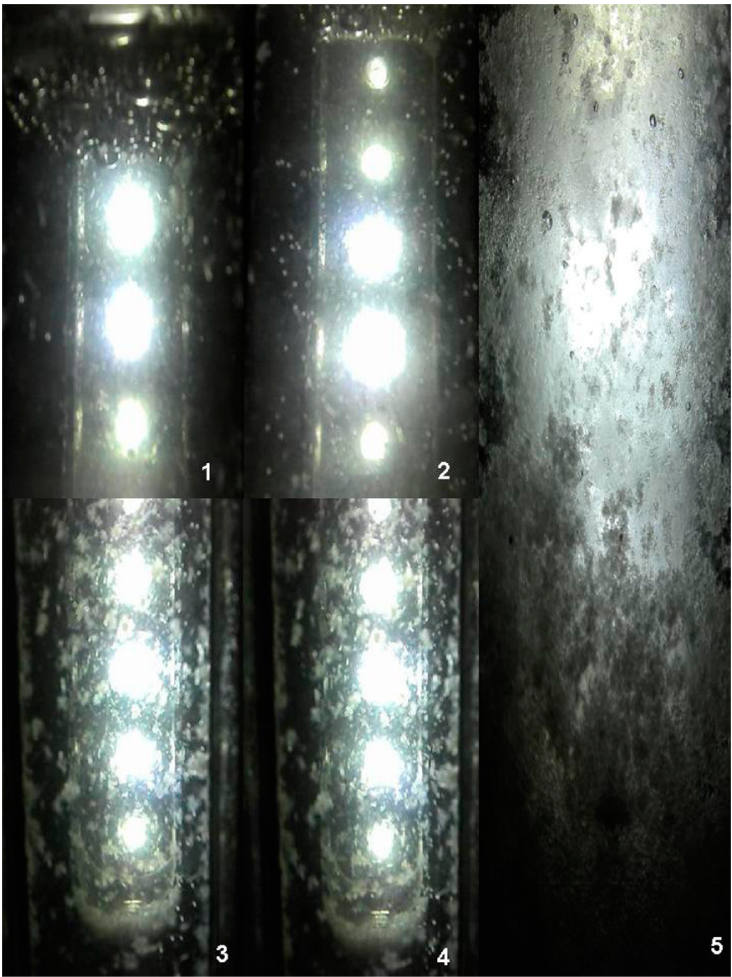

Figure 6. Pictures of the hydrate formation process in the scaled-up equipment at $3.0 \mathrm{MPa}$ and $274.65 \mathrm{~K}$.

following results and discussion are centered on the experiments with a volume ratio of 0.75 .

Figure 8 shows how the pressure in the reactor changes with time in the bubbling experiments at $274.65 \mathrm{~K}$. In these experiments, the gas flow rate is set at $6.75 \mathrm{~mL} \mathrm{~min}^{-1} \mathrm{~L}^{-1}$ according to our previous work. ${ }^{27}$ In Figure 8 , the pressure changes in the experiments with and without the $4 \mathrm{~K}$ temperature fluctuation are also compared. The pressure in the reactor increases with the temperature. With the temperature decrease and recovery to $T^{\prime}$, the pressure decreases synchronously. However, as seen from Figure 8, the pressure curve does not appear to be consistent with the pressure curve achieved from the 


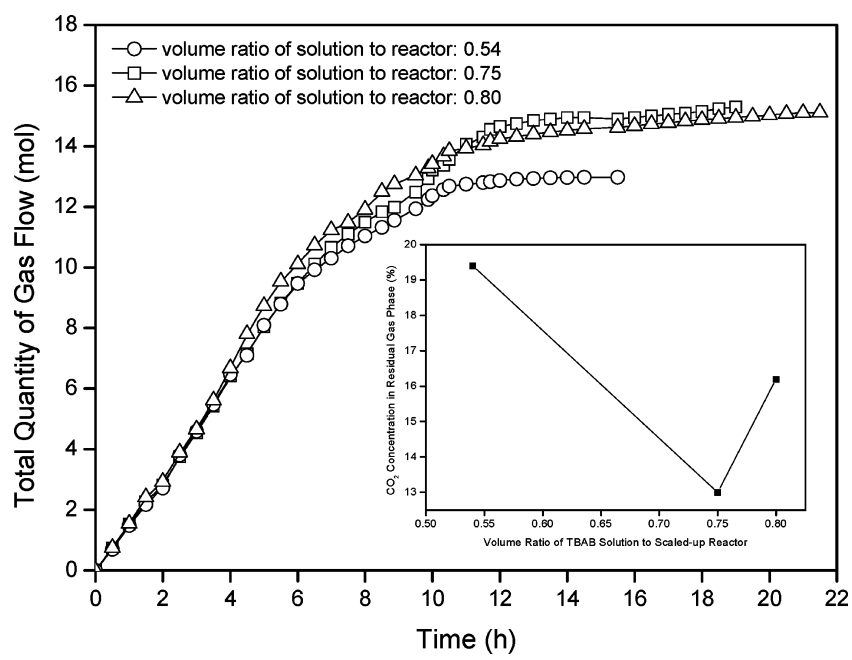

Figure 7. Total quantity of gas flow changes with time at different volume ratios of $\mathrm{TBAB}$ solution to the scaled-up reactor in the bubbling experiment at $274.65 \mathrm{~K}$ and $3.0 \mathrm{MPa}$.

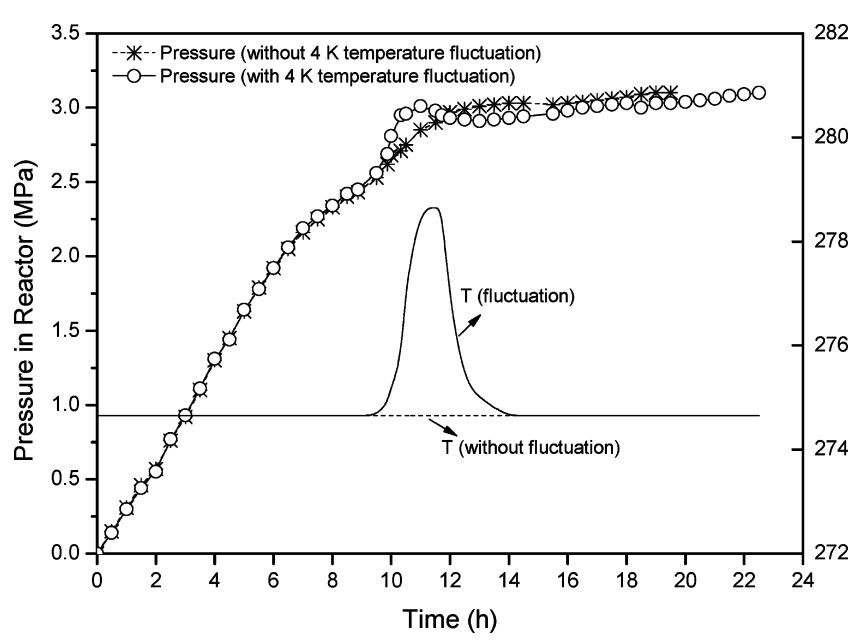

Figure 8. Comparison of pressures in the scaled-up reactor change with time in the bubbling experiments at $274.65 \mathrm{~K}$ (gas flow rate at $6.75 \mathrm{~mL}$ $\left.\min ^{-1} L^{-1}\right)$.

experiment without a temperature fluctuation. It is lower after the temperature recovers to $T^{\prime}$. It takes a longer time to reach $3.10 \mathrm{MPa}$, which is set in advance. It indicates that the temperature fluctuation results in more gas dissolving into the solution and being encaged into the gas hydrates. The total quantities of gas flow obtained from the experiments both with and without temperature fluctuations are shown in Figure 9. As seen from Figure 9, the total quantity of gas flow obtained from the experiment with a temperature fluctuation is approximately $15 \%$ more than that obtained from the experiment without temperature fluctuation. It further proves that the temperature fluctuation does promote the gas hydrate formation in the scaledup equipment.

In addition, to prove that the scaled-up equipment design is relevant to hydrate-based $\mathrm{CO}_{2}$ separation, the comparisons of total gas consumed in the reactor and $\mathrm{CO}_{2}$ concentration in the residual gas phase are made, and the detail comparisons are shown in Table 2. As seen from Table 2, the gas consumed in the scaled-up equipment is approximately 50 times of that in the small experimental apparatus. As calculated according to the above data, the volumes of the gas phase in the experiments with

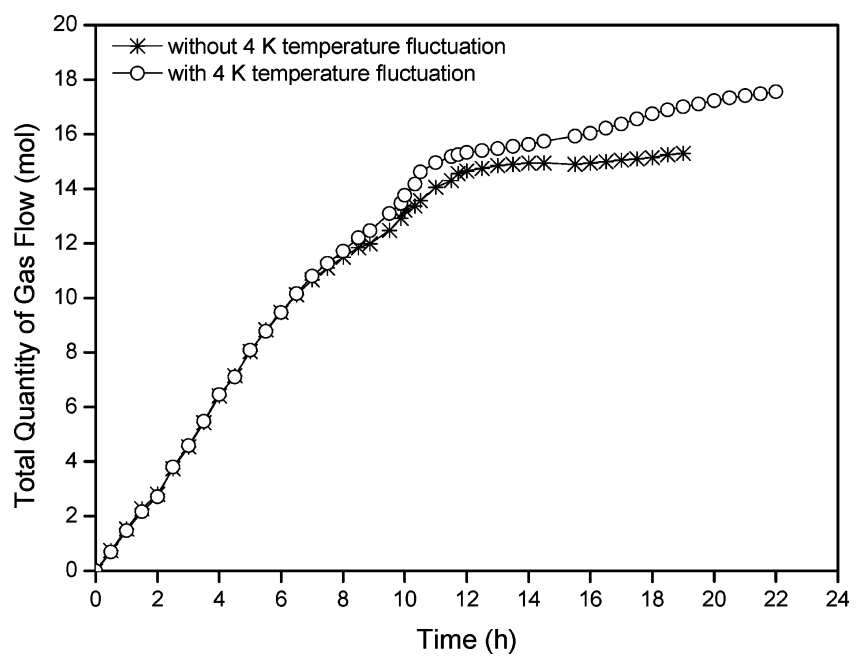

Figure 9. Total quantity of gas flow comparison between the bubbling experiments with and without temperature fluctuation in scaled-up equipment at $274.65 \mathrm{~K}$.

Table 2. Comparison of Total Gas Consumed in the Reactor and $\mathrm{CO}_{2}$ Concentration in the Residual Gas Phase Achieved from Bubbling Experiments Conducted in the Small Apparatus and the Scaled-Up Equipment

\begin{tabular}{|c|c|c|}
\hline experiment & $\begin{array}{l}\text { total gas con- } \\
\text { sumed in the } \\
\text { reactor }(\mathrm{mol})\end{array}$ & $\begin{array}{l}\mathrm{CO}_{2} \text { concentra- } \\
\text { tion in the resid- } \\
\text { ual gas phase (\%) }\end{array}$ \\
\hline $\begin{array}{l}180 \mathrm{~mL} \text { of TBAB solution in a } 336 \mathrm{~mL} \text { reactor } \\
\text { at } 3.0 \mathrm{MPa} \text { and } 274.65 \mathrm{~K} \text {, bubbling, without } \\
\text { temperature fluctuation }\end{array}$ & 0.330 & 11.4 \\
\hline $\begin{array}{l}180 \mathrm{~mL} \text { of TBAB solution in a } 336 \mathrm{~mL} \text { reactor } \\
\text { at } 3.0 \mathrm{MPa} \text { and } 274.65 \mathrm{~K} \text {, bubbling, with } 4 \mathrm{~K} \\
\text { temperature fluctuation }\end{array}$ & 0.351 & 7.7 \\
\hline $\begin{array}{l}30 \mathrm{~L} \text { of TBAB solution in a } 40 \mathrm{~L} \text { scaled-up } \\
\text { reactor at } 3.0 \mathrm{MPa} \text { and } 274.65 \mathrm{~K} \text {, bubbling, } \\
\text { without temperature fluctuation }\end{array}$ & 15.3 & 13.2 \\
\hline $\begin{array}{l}30 \mathrm{~L} \text { of TBAB solution in a } 40 \mathrm{~L} \text { scaled-up } \\
\text { reactor at } 3.0 \mathrm{MPa} \text { and } 274.65 \mathrm{~K} \text {, bubbling, } \\
\text { with } 4 \mathrm{~K} \text { temperature fluctuation }\end{array}$ & 17.6 & 8.9 \\
\hline
\end{tabular}

the small reactor and the scaled-up reactor are $156 \mathrm{~mL}$ and $10 \mathrm{~L}$; i.e., the volume of the gas phase in the experiment with the scaled-up reactor is approximately 64 times that with the small reactor. There is some small discrepancy between the factors of 50 and 64. Despite this small discrepancy, we still consider that the scaled-up equipment is a feasible route to the hydrate-based $\mathrm{CO}_{2}$ separation from IGCC synthesis gas because the results obtained from the scaled-up equipment are quite consistent with those obtained from the small apparatus. For example, the $\mathrm{CO}_{2}$ concentrations in the residual gas phase at the end of the experiments with or without temperature fluctuation in the scaled-up equipment are 8.9 and $13.0 \%$, which are approximately 13.5 and $12.3 \%$ higher than those obtained in the experiments conducted in the small apparatus under the same conditions.

\section{CONCLUSION}

In this work, the effects of stirring and bubbling on hydrate-based $\mathrm{CO}_{2}$ separation from IGCC synthesis gas are compared with and without temperature fluctuations in a small experimental apparatus. The optimal volume ratio of solution to the reactor is determined in a scaled-up reactor. An integrated process of bubbling in conjunction with a temperature fluctuation is conducted in the scaled-up equipment. The experimental results 
indicate that bubbling has an effect on the $\mathrm{CO}_{2}$ separation very similar to stirring. The optimal volume ratio of TBAB solution to the reactor for $\mathrm{CO}_{2}$ separation shifts to 0.75 after the volume of the reactor is enlarged 100-fold. The temperature fluctuation has a positive effect on hydrate formation in the scaled-up equipment very similar to that observed in the small experimental apparatus. When the volume ratio of $0.29 \mathrm{~mol} \% \mathrm{TBAB}$ solution to the scaled-up reactor volume is 0.75 , the total quantity of gas flow achieved in the experiment is $15.3 \mathrm{~mol}$ and the $\mathrm{CO}_{2}$ concentration in the residual gas phase drops from $40.0 \%$ in the feed gas mixture to $13.2 \%$ at the end of gas hydrate formation. The results demonstrate the benefits of the integrated process and that scale-up of such processing equipment is feasible for hydrate-based $\mathrm{CO}_{2}$ separation from IGCC synthesis gas. The work offers experimental data that should aid the industrial development of the hydrate-based $\mathrm{CO}_{2}$ separation process in the future.

\section{AUTHOR INFORMATION}

\section{Corresponding Author}

*Telephone: +86-20-87057037. Fax: +86-20-87034664. E-mail: lixs@ms.giec.ac.cn.

\section{Notes}

The authors declare no competing financial interest.

\section{ACKNOWLEDGMENTS}

This work was supported by the National Natural Science Foundation of China (51076155) and the Science and Technology Program of Guangdong Province (2009B050600006), which are gratefully acknowledged.

\section{REFERENCES}

(1) Freund, P.; Ormerod, W. G. Progress toward storage of carbon dioxide. Energy Convers. Manage. 1997, 38, S199-S204.

(2) Duc, N. H.; Chauvy, F.; Herri, J. M. $\mathrm{CO}_{2}$ capture by hydrate crystallization-A potential solution for gas emission of steelmaking industry. Energy Convers. Manage. 2007, 48 (4), 1313-1322.

(3) Sloan, E. D. Clathrate Hydrates of Natural Gases, 3rd ed.; CRC Press: Golden, CO, 2008; p 721.

(4) Lee, H. H.; Ahn, S. H.; Nam, B. U.; Kim, B. S.; Lee, G. W.; Moon, D.; Shin, H. J.; Han, K. W.; Yoon, J. H. Thermodynamic stability, spectroscopic identification, and gas storage capacity of $\mathrm{CO}_{2}-\mathrm{CH}_{4}-\mathrm{N}_{2}$ mixture gas hydrates: Implications for landfill gas hydrates. Environ. Sci. Technol. 2012, 46 (7), 4184-4190.

(5) Koh, C. A.; Sloan, E. D. Natural gas hydrates: Recent advances and challenges in energy and environmental applications. AIChE J. 2007, 53 (7), 1636-1643.

(6) Kang, S. P.; Lee, H.; Lee, C. S.; Sung, W. M. Hydrate phase equilibria of the guest mixtures containing $\mathrm{CO}_{2}, \mathrm{~N}_{2}$ and tetrahydrofuran. Fluid Phase Equilib. 2001, 185 (1-2), 101-109.

(7) Sugahara, T.; Murayama, S.; Hashimoto, S.; Ohgaki, K. Phase equilibria for $\mathrm{H}_{2}+\mathrm{CO}_{2}+\mathrm{H}_{2} \mathrm{O}$ system containing gas hydrates. Fluid Phase Equilib. 2005, 233 (2), 190-193.

(8) Seo, Y. T.; Moudrakovski, I. L.; Ripmeester, J. A.; Lee, J. W.; Lee, H. Efficient recovery of $\mathrm{CO}_{2}$ from flue gas by clathrate hydrate formation in porous silica gels. Environ. Sci. Technol. 2005, 39 (7), 2315-2319.

(9) Strobel, T. A.; Koh, C. A.; Sloan, E. D. Hydrogen storage properties of clathrate hydrate materials. Fluid Phase Equilib. 2007, 261 (1-2), 382-389.

(10) Sloan, E. D. Introductory overview: Hydrate knowledge development. Am. Mineral. 2004, 89 (8-9), 1155-1161.

(11) Spencer, D. F. Methods of selectively separating $\mathrm{CO}_{2}$ from a multicomponent gaseous stream. U.S. Patent 6,090,186, 1997.
(12) Kang, S. P.; Lee, H. Recovery of $\mathrm{CO}_{2}$ from flue gas using gas hydrate: Thermodynamic verification through phase equilibrium measurements. Environ. Sci. Technol. 2000, 34 (20), 4397-4400.

(13) Kumar, R; Wu, H. J.; Englezos, P. Incipient hydrate phase equilibrium for gas mixtures containing hydrogen, carbon dioxide and propane. Fluid Phase Equilib. 2006, 244 (2), 167-171.

(14) Hashimoto, S.; Murayama, S.; Sugahara, T.; Ohgaki, K. Phase equilibria for $\mathrm{H}_{2}$ plus $\mathrm{CO}_{2}$ plus tetrahydrofuran plus water mixtures containing gas hydrates. J. Chem. Eng. Data 2006, 51 (5), 1884-1886.

(15) Zhang, J. S.; Lee, J. W. Equilibrium of hydrogen plus cyclopentane and carbon dioxide plus cyclopentane binary hydrates. J. Chem. Eng. Data 2009, 54 (2), 659-661.

(16) Li, X. S.; Xia, Z. M.; Chen, Z. Y.; Yan, K. F.; Li, G.; Wu, H. J. Equilibrium hydrate formation conditions for the mixtures of $\mathrm{CO}_{2}+\mathrm{H}_{2}$ + tetrabutyl ammonium bromide. J. Chem. Eng. Data 2010, 55 (6), 2180-2184.

(17) Linga, P.; Adeyemo, A.; Englezos, P. Medium-pressure clathrate hydrate/membrane hybrid process for postcombustion capture of carbon dioxide. Environ. Sci. Technol. 2008, 42 (1), 315-320.

(18) Linga, P.; Kumar, R.; Englezos, P. The clathrate hydrate process for post and pre-combustion capture of carbon dioxide. J. Hazard. Mater. 2007, 149 (3), 625-629.

(19) Li, X. S.; Xu, C. G.; Chen, Z. Y.; Wu, H. J. Tetra- $n$-butyl ammonium bromide semi-clathrate hydrate process for post-combustion capture of carbon dioxide in the presence of dodecyl trimethyl ammonium chloride. Energy 2010, 35 (9), 3902-3908.

(20) Li, X. S.; Xu, C. G.; Chen, Z. Y.; Wu, H. J. Hydrate-based precombustion carbon dioxide capture process in the system with tetra- $n$ butyl ammonium bromide solution in the presence of cyclopentane. Energy 2011, 36, 10.

(21) Maini, B. B.; Bishnoi, P. R. Experimental investigation of hydrate formation behavior of a natural-gas bubble in a simulated deep-sea environment. Chem. Eng. Sci. 1981, 36 (1), 183-189.

(22) Ohmura, R.; Kashiwazaki, S.; Shiota, S.; Tsuji, H.; Mori, Y. H. Structure-I and structure- $\mathrm{H}$ hydrate formation using water spraying. Energy Fuels 2002, 16 (5), 1141-1147.

(23) Skovborg, P.; Ng, H. J.; Rasmussen, P.; Mohn, U. Measurement of induction times for the formation of methane and ethane gas hydrates. Chem. Eng. Sci. 1993, 48 (3), 445-453.

(24) Englezos, P.; Kalogerakis, N.; Dholabhai, P. D.; Bishnoi, P. R. Kinetics of gas hydrate formation from mixtures of methane and ethane. Chem. Eng. Sci. 1987, 42 (11), 2659-2666.

(25) Fukumoto, K.; Tobe, J.; Ohmura, R.; Mori, Y. H. Hydrate formation using water spraying in a hydrophobic gas: A preliminary study. AIChE J. 2001, 47 (8), 1899-1904.

(26) Kojima, R.; Yamane, K.; Aya, I. Dual nature of $\mathrm{CO}_{2}$ solubility in hydrate forming region. Greenhouse Gas Control Technol., Proc. Int. Conf., 7th 2003, 1 and 2, 825-830.

(27) Xu, C. G.; Li, X. S.; Lv, Q. N.; Chen, Z. Y.; Cai, J. Hydrate-based $\mathrm{CO}_{2}$ (carbon dioxide) capture from IGCC (integrated gasification combined cycle) synthesis gas using bubble method with a set of visual equipment. Energy 2012, 9.

(28) Li, X. S.; Xu, C. G.; Chen, Z. Y.; Wu, H. J.; Cai, J. Effect of temperature fluctuation on hydrate-based $\mathrm{CO}_{2}$ separation from fuel gas. J. Nat. Gas Chem. 2011, 20 (6), 647-653.

(29) Linga, P.; Kumar, R. N.; Englezos, P. Gas hydrate formation from hydrogen/carbon dioxide and nitrogen/carbon dioxide gas mixtures. Chem. Eng. Sci. 2007, 62 (16), 4268-4276.

(30) Smith, J. M.; Van Ness, H. C.; Abbott, M. M. Introduction to Chemical Engineering Thermodynamics; McGraw-Hill, Inc.: New York, 2001. 